\title{
Are there any differences in the provided burn care between men and women? A retrospective study
}

\author{
Laura Pompermaier ${ }^{1,2,5^{*}}$, Moustafa Elmasry ${ }^{1,2}$, Islam Abdelrahman ${ }^{2,3}$, Mats Fredrikson ${ }^{2}$, Folke Sjöberg ${ }^{1,2,4}$ \\ and Ingrid Steinvall ${ }^{1,2}$
}

\begin{abstract}
Background: Disparity between medical treatment for men and women has been recorded worldwide. However, it is difficult to find out if the disparities in both the use of resources and outcome depend entirely on sex-related discrimination. Our aim was to investigate if there are differences in burn treatments between the sexes.

Methods: All patients admitted with burns to Linköping University Hospital during the 16-year period 2000-2015 were included. Interventions were prospectively recorded using the validated Burn SCoring system (BSC). Data were analysed using a multivariable panel regression model adjusted for age, percentage total body surface area (\%TBSA), and in-hospital mortality.

Results: A total of 1363 patients were included, who generated a total of 22,301 daily recordings while they were inpatients. Males were 70\% (930/1363). Sex was not an independent factor for daily scores after adjustment for age, $\%$ TBSA, and mortality in hospital (model $R^{2}=0.60, p<0.001$ ).

Conclusion: We found no evidence of inequity between the sexes in treatments given in our burn centre when we had adjusted for size of burn, age, and mortality. BSC seems to be an appropriate model in which to evaluate sex-related differences in the delivery of treatments.
\end{abstract}

Keywords: Burn care, Intervention score, Sex, Trauma model, Workload

\section{Background}

In many parts of the world, disparity between the sexes in health care is a reality, with both higher expenditure on health care and a survival advantage for men [1]. In other parts of the world, such differences are less obvious [2-5].

However, it is difficult to find out if the sex-related disparity in medical treatment given depends solely on sex-related discrimination, or if there are possible differences in the underlying medical conditions and their severity [6]. Patients with burns provide an ideal opportunity to study sex-related differences in both interventions and outcomes.

\footnotetext{
* Correspondence: laurapompermaier@hotmail.com

${ }^{1}$ Department of Plastic Surgery, Hand Surgery, and Burns, Linköping

University, Linköping, Sweden

${ }^{2}$ Department of Clinical and Experimental Medicine, Linköping University,

Linköping, Sweden

Full list of author information is available at the end of the article
}

Outcome has been shown by many authors to be related to size of burn and age [7-9], which are strong indicators of severity of illness and underlying medical conditions [7], and the differences in the delivery of medical treatment among sexes can be properly studied using the same variables. Patients with burns are also likely to be cared for in a standard manner and monitored for daily care and treatment.

Sex disparity in the incidence of burns depends on demographic factors, such as age or behaviour, or both, and the causes differ worldwide because of diverse socioeconomic conditions [10]. Scalds and contact burns are the most common thermal injuries in children, regardless of sex [11, 12]; work-related flame burns are most prevalent in adult men; and scalds, inhalation injury, or contact burns that occur at home are the most common causes among adult women internationally [13-16]. Adult women have been reported to be at a disadvantage

(C) The Author(s). 2018 Open Access This article is distributed under the terms of the Creative Commons Attribution 4.0 International License (http://creativecommons.org/licenses/by/4.0/), which permits unrestricted use, distribution, and 
as far as survival after burns is concerned in both past and recent studies [14, 16-20], whereas mortality in hospital in Sweden is independent of sex [7, 21].

It has recently been reported that the amount of resources used for the care of patients in Swedish general intensive care has been to the benefit of the men [22], and for this reason, it would be interesting to analyse whether the requirement or delivery of treatment to burned patients is equal between the sexes.

The therapeutic Burn SCoring system (BSC) has been designed in 1992 at our centre to assess the medical interventions made on each patient, as well as to calculate the cost of each patient's treatment [23]. It has developed principally from the Nursing Care Recording system, which is an intervention scoring system built for general intensive care, including burn-specific items, such as burn excisions, skin grafting, and change of dressing. To validate the BSC, the scores obtained from the same patient with the BSC were compared with those obtained with the validated Therapeutic Intervention Scoring System (TISS), showing good agreement in the assessment of level of care. Furthermore, the BSC has been described in a recent publication about the use of resources in relation to outcome (mortality) [24].

The aim of the present study was to investigate potential differences between the treatment of men and women in intensive care as well as in the general ward. We used total daily recordings of the BSC (for each patient) for analysis, and adjusted for age, percentage total body surface area (\%TBSA), and in-hospital mortality.

\section{Methods}

All patients admitted to Linköping University Hospital Burn Centre since 1 January 2000 and discharged before the 10 November 2015 were included. We analysed the data that were recorded in the prospectively maintained burn registry [23]. The study was approved by the Regional Ethics Review Board in Linköping (No.2013/341-31).

Patients were treated with early excision and grafting [23], and revision of the wound every second day. The patients with the most severe burns and those who required intensive care for other reasons were treated with standard ventilation [25, 26], fluid management [27], and early enteral nutrition.

Those with minor burns had early tangential excision, and the burn was covered with meshed split-thickness skin grafts. Major burns were treated by staged excisions and covered with xenografts to allow clear demarcation of the wound bed, followed by a later autografting [28-30]. All the procedures, whether operations or dressings under sedation, were done within the burn centre's operating rooms and handled by the staff of the unit, except for intraoperative duties such as anaesthesia and scrubbing.
General variables measured and included in the study are as follows: \%TBSA, cause of injury, age, sex, duration of hospital stay, and survival. Mortality was defined as death from any cause during admission to the burn centre. The BSC covers the following categories of care: surveillance, respiration, circulation, wound care, mobilisation, laboratory tests, infusions, and operations [23]. Each category is given a score from 0 to 4 depending on the level of care, from the less challenging $(\mathrm{BSC}=0)$ to the most (BSC $=4)$. An exception is the scoring of the operation, which is calculated based on the operating time and $1 \mathrm{~h}$ equals a score of $2,2 \mathrm{~h}$ a score of 4 , etc. In practice, the more points are scored, the more has been the work done.

Daily BSC refers to the score recorded for each patient every $24 \mathrm{~h}$, and total BSC refers to the sum of the daily BSC points for each patient.

We defined patients who required intensive care as those who needed mechanical ventilation during their stay at the burn centre, and days in intensive care as those days when patients in the unit required mechanical ventilation.

\section{Analysis of data and statistics}

Data were analysed with STATA (STATA v12.0, Stata Corp. LP College Station, TX, USA) and presented as median (10-90 centiles) unless otherwise stated. The significance of differences in characteristics was assessed with the Mann-Whitney $U$ test and the chi-square test unless otherwise stated. Simple linear regression was used for the scattergrams. As the hypothesis was that there was no difference between the treatment given to men and women, we did a non-inferiority analysis using 1 BSC point/day as the limit (delta). A multivariable regression for panel data (panel variable by patient) was used for the analysis of the association between sex and daily BSC points. A subgroup analysis was done for the patients in intensive care using the same regression model. Probabilities of less than 0.05 were accepted as significant.

\section{Results}

The data from 1363 patients were analysed based on 22,301 daily inpatient recordings of BSC. The median age was 33 years (10th-90th centiles, 1-72), \%TBSA was 7\% (10th-90th centiles, 1-31), 960 of the 1363 were male (70\%), and crude mortality was $5.1 \%$. There were no differences between the groups of male and female patients regarding total BSC points/patient, BSC points by the eight BSC categories, duration of hospital stay, mortality, size of the burn, or age (Table 1).

Figure 1 shows the mean daily BSC points among the patients who survived, according to their ages and \%TBSA groups. Significant differences (unadjusted) between male and female patients were found in one age group (46-65.9 years, $p=0.046)$ and one \%TBSA group $(0-0.9 \%, p=0.02)$. 
Table 1 Details of the patients admitted with burns during 2000-2015

\begin{tabular}{|c|c|c|c|c|c|}
\hline & Female & & Male patients & & $p$ value \\
\hline No. of patients & 403 & & 960 & & \\
\hline Age (years) & 29.6 & $1.2-76.2$ & 33.9 & $1.3-71.4$ & 0.10 \\
\hline TBSA burned (\%) & 7.0 & $1.0-27.0$ & 6.4 & $1.0-32.8$ & 0.37 \\
\hline Hospital stay (days) & 7.0 & $2.0-39.0$ & 8.0 & $2.0-35.0$ & 0.52 \\
\hline No. of deaths & $25(6)$ & & $45(5)$ & & 0.25 \\
\hline No. who required mechanical ventilation & $83(21)$ & & $195(20)$ & & 0.91 \\
\hline \multicolumn{6}{|l|}{ BSC categories } \\
\hline Surveillance & 4.0 & $0.0-57.0$ & 3.0 & $0.0-57.0$ & 0.23 \\
\hline Respiration & 1.0 & $0.0-44.0$ & 0.0 & $0.0-40.5$ & 0.54 \\
\hline Circulation & 0.0 & $0.0-9.0$ & 0.0 & $0.0-7.5$ & 0.22 \\
\hline Wound care & 11.0 & $1.0-66.0$ & 11.0 & $1.0-60.0$ & 0.65 \\
\hline Mobilisation & 9.0 & $2.0-66.0$ & 8.0 & $2.0-62.0$ & 0.41 \\
\hline Laboratory tests & 1.0 & $0.0-26.0$ & 2.0 & $0.0-28.0$ & 0.42 \\
\hline Infusions & 4.0 & $0.0-55.0$ & 3.0 & $0.0-62.5$ & 0.65 \\
\hline Operation & 4.0 & $0.0-24.0$ & 4.0 & $0.0-33.0$ & 0.73 \\
\hline Total BSC points & 36.0 & $7.0-350.0$ & 34.0 & $7.0-345.0$ & 0.37 \\
\hline
\end{tabular}

TBSA total body surface area, BSC Burn SCoring system

Data are presented as median and 10th-90th centiles or number and percentage

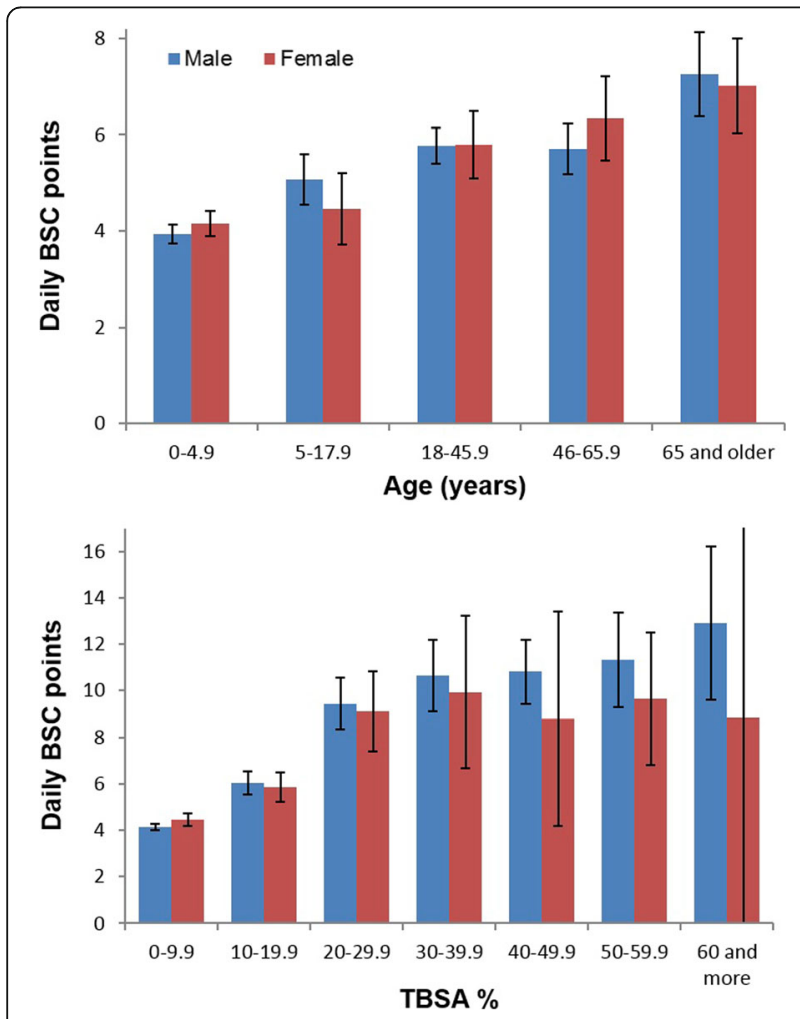

Fig. 1 Mean (95\% confidence interval) daily Burn SCoring system (BSC) points among the patients who survived. Upper figure: subgroups by age, lower figure: by \%TBSA groups.
The unadjusted mean difference was $0.8 \mathrm{BSC}$ points/day higher in the male group (mean (SD) 8.9 (7.5)) compared with the female group (mean (SD) 8.1 (6.6)) when we analysed the 22,301 daily recordings ( $t$ test, $p<0.001$ ). Non-inferiority analysis showed that if there was no difference in daily BSC between male and female patients, then 1778 recordings would be required to be $90 \%$ sure that the upper limit of a one-sided $95 \%$ confidence interval (CI) (or equivalently a 90\% two-sided CI) will be below the non-inferiority limit of 1 (SD of outcome 7.2). When using the actual mean difference 0.8 , the required number was 2776 recordings, which is one eighth of the 22,301 that we used in the regression model.

The multivariable regression model showed that sex was not an independent factor for daily BSC points (Table 2), which increased with the size of the burn, in older patients and for those that died during their admission.

We also tested to add the type of burn (hot object, chemicals, flame, electricity, and others) in our regression model but it did not change the result (coefficient for sex (male) $=0.09, p=0.41$ ). The subgroup analysis of the 278 patients who required intensive care showed similar results, in that there was no difference in the number of daily BSC points between male and female patients during the period of intensive care (Table 3).

\section{Discussion}

We have analysed 22,301 daily intervention score recordings using a multivariable regression model to 
Table 2 The association between sex and daily Burn SCoring system points, adjusted for total body surface area (TBSA) burned, age, and deaths

\begin{tabular}{lllll}
\hline & Coefficient & SE & $p$ value & $95 \% \mathrm{Cl}$ \\
\hline $\begin{array}{l}\text { TBSA burned (\%) } \\
\text { 0-9.9 }\end{array}$ & & & & \\
10-19.9 & 1.89 & 0.14 & $<0.001$ & 1.62 to 2.16 \\
20-29.9 & 4.98 & 0.17 & $<0.001$ & 4.65 to 5.31 \\
30-39.9 & 6.15 & 0.20 & $<0.001$ & 5.75 to 6.55 \\
40-49.9 & 6.59 & 0.25 & $<0.001$ & 6.10 to 7.09 \\
50-59.9 & 6.36 & 0.26 & $<0.001$ & 5.85 to 6.87 \\
60 and more & 8.06 & 0.28 & $<0.001$ & 7.52 to 8.60 \\
Age (years) & & & & \\
0-4.9 & & & & \\
5-17.9 & -0.38 & 0.23 & 0.10 & -0.84 to 0.07 \\
18-45.9 & 1.21 & 0.18 & $<0.001$ & 0.87 to 1.56 \\
46-65.9 & 2.00 & 0.18 & $<0.001$ & 1.65 to 2.35 \\
65 and older & 3.04 & 0.19 & $<0.001$ & 2.67 to 3.42 \\
Sex (male) & 0.12 & 0.12 & 0.30 & -0.11 to 0.34 \\
Mortality & 6.44 & 0.25 & $<0.001$ & 5.95 to 6.93 \\
Constant & 3.06 & 0.17 & $<0.001$ & 2.74 to 3.39 \\
\hline SE standard & & &
\end{tabular}

SE standard error, $\mathrm{Cl}$ confidence interval

Multivariable regression for panel data, model (between) $R^{2}=0.60, p<0.001$. Patients $n=1363$, daily recordings $n=22,301$

Table 3 The association between sex and daily Burn SCoring system (BSC) points during the period of intensive care (treatment with mechanical ventilation)

\begin{tabular}{lllll}
\hline & Coefficient & SE & $p$ value & $95 \% \mathrm{Cl}$ \\
\hline $\begin{array}{l}\text { TBSA burned (\%) } \\
\text { 0-9.9 }\end{array}$ & & & & \\
$10-19.9$ & 1.55 & 0.68 & 0.02 & 0.21 to 2.89 \\
20-29.9 & 2.25 & 0.62 & $<0.001$ & 1.04 to 3.45 \\
30-39.9 & 2.83 & 0.65 & $<0.001$ & 1.56 to 4.10 \\
40-49.9 & 3.30 & 0.71 & $<0.001$ & 1.92 to 4.68 \\
50-59.9 & 2.88 & 0.74 & $<0.001$ & 1.44 to 4.32 \\
60 and more & 4.11 & 0.71 & $<0.001$ & 2.72 to 5.49 \\
Age (years) & & & & \\
0-4.9 & & & & \\
5-17.9 & 2.93 & 1.17 & 0.01 & 0.65 to 5.22 \\
18-45.9 & 3.71 & 0.97 & $<0.001$ & 1.81 to 5.61 \\
46-65.9 & 3.51 & 0.96 & $<0.001$ & 1.62 to 5.40 \\
65 years and over & 2.70 & 1.00 & 0.007 & 0.74 to 4.66 \\
Sex (male) & -0.07 & 0.33 & 0.83 & -0.72 to 0.58 \\
Mortality & 2.13 & 0.41 & $<0.001$ & 1.33 to 2.93 \\
Constant & 12.89 & 1.08 & $<0.001$ & 10.76 to 15.01 \\
\hline SE standard eror Cl con & & & &
\end{tabular}

SE standard error, $C l$ confidence interval, TBSA total body surface area Multivariable regression for panel data, model (between) $R^{2}=0.16, p<0.001$. Patients $n=278$, daily recordings $n=4427$ adjust for size of burn, age, and mortality, and we have found no evidence of inequity among sexes in treatments given in our burn centre.

Measurements of the workload in general intensive care units have been used to measure the quality of care [31-33]. Systems designed to "score" different treatments of burns are few, and those currently available tend to depict local policies of care $[34,35]$ and are designed for use in general intensive care units $[16,36$, 37]. In particular, management of the wound is an activity specific to the care of burns that is vital, and must be incorporated in the measurement of workload [37, 38].

The BSC was developed to remedy this deficiency, and we have used it to analyse the delivery of care. Assuming that the causes of burns differ between sexes [39], we investigated whether different types of burns (flame, scald, chemical, and electrical) influence treatment at the burn centre and we found that they did not.

However, patients with burns provide an excellent model for the study of sex-related differences in both interventions and outcomes, as the group is homogeneous with a common cause for admission (the burn), the time of the injury is known, the medical care is relatively standard, and $97 \%$ of the mortality may be explained by the two variables \%TBSA and age [40]. Furthermore, age is a good surrogate marker for coexisting disease [7] and \%TBSA for burn severity and can be quantified $[17,29]$.

Several international studies have reported that adult men have a survival advantage after burns [14-19], which is in contrast to our finding that the sex of the patient does not seem to be an independent factor for mortality among patients with burns [7, 21]. It is not possible to deduce if this is caused by the underlying severity of injury or by differences in treatment, as the studies mentioned above did not include treatments in their analysis.

In a recent Swedish study, male patients have been shown to receive better care than women in general intensive care units. We could not confirm this inequity among intensive care patients with burns in our subgroup analysis, despite Swedish general intensive care units and those specifically for patients with burns are thought to be comparable and their routines are similar. Both are managed by intensive care physicians who work in both the general intensive care unit and the intensive care unit at the burn centre. The intervention scoring system currently in use in general intensive care units [22] and the BSC [23] are both modified versions of the original Nursing Care Recording system [41] and are consequently regarded as equivalent. These conflicting findings could possibly be explained by the use of different methods to adjust for the severity of illness. Samuelsson et al. [22] used the Simplified Acute Physiology Score III (SAPS III) to adjust for severity of illness, whereas we used the \%TBSA, which is an excellent measure of the severity of a burn $[9,40]$, being more 
sensitive and having a greater degree of accuracy. It would, however, have been interesting to test if we would have found differences in provided burn care between men and women, using the SAPS III as this possibly would have resulted in an insufficient adjustment. Unfortunately, SAPS III is not recorded in our database.

\section{Limitations of the study}

Firstly, although the BSC is a detailed scoring system with its seven care categories, it cannot be considered to be complete. It may be that it is not detailed enough to detect possible differences in care, but it has been found to correlate closely with the TISS, which is a detailed system with 36 different scores, and so may still be claimed to be a valid instrument. Secondly, this study was a single-centre investigation made in a country with a limited and quite homogeneous population, and this may reduce the generalizability of its conclusions. However, patients with burns admitted to our centre comprise all patients with burns without exclusion for age, sex, severity of burn, or cause of injury, and some global similarities, such as the decreases in the incidence of burns; the severity of injury, mortality, and the duration of stay [42], give value to our results. Yet, using the same intervention scoring system in other burn centres with outcome figures different than ours would be interesting to validate this instrument. Thirdly, although the treatments at the burn centre have been repeatedly investigated and the results published, and there have been improvements in outcome during the duration of this study [24], there may also be a time-related effect. From a scientific point of view, however, it is unlikely that this would affect the sex-related treatments being studied. Fourthly, large volumes of daily recordings made over time always carry a risk of the results being faulty and inconsistent. For this particular study, we claim that this is less likely as a well-known score has been used, and the categories would be difficult to judge other than objectively.

\section{Conclusion}

This is the first study to our knowledge that has investigated whether there are sex-related differences in the treatments given over a long period of time to patients with burns. It is the second from this unit in which we have studied sex-related differences in outcome in a strictly adjusted model. In line with the previous publication, in which a similar mortality between the sexes was recorded, we have been unable to find data that indicate inequities between the sexes in the treatments provided. The model of burns, in which detailed adjustments can be made for severity of illness and pre-existing medical conditions, seems to be suitable for the evaluation of sex-related differences in the delivery of medical care.

\section{Availability of data and materials}

The dataset used and/or analysed during the current study are available from the corresponding author on request. The manuscript, including related data, figures, and tables, has not been previously published and that the manuscript is not under consideration elsewhere.

\section{Authors' contributions}

All authors have made substantial contributions. LP, ME, IA, and IS participated in the design of the study, collected the data, and did the statistical analysis and interpretation of data. LP drafted the manuscript. FS conceived the study and participated in its design, interpretation of data, and drafting of the manuscript. MF supervised the statistical analysis. All authors have made final approval of the version to be submitted.

Ethics approval and consent to participate

The study was approved by the Regional Ethics Review Board in Linköping (No.2013/341-31).

\section{Consent for publication}

N/A.

\section{Competing interests}

The authors declare that they have no competing interests.

\section{Author details}

'Department of Plastic Surgery, Hand Surgery, and Burns, Linköping University, Linköping, Sweden. ${ }^{2}$ Department of Clinical and Experimental Medicine, Linköping University, Linköping, Sweden. ${ }^{3}$ Department of Surgery, Plastic Surgery Unit, Suez Canal University, Ismailia, Egypt. ${ }^{4}$ Department of Anaesthesia and Intensive Care, Linköping University, Linköping, Sweden. ${ }^{5}$ the Burn Centre, Linköping University Hospital, 58185 Linköping, Sweden.

Received: 14 May 2018 Accepted: 13 July 2018

Published online: 13 August 2018

\section{References}

1. Saikia N, Moradhvaj BJK. Gender difference in health-care expenditure: evidence from India human development survey. PLoS One. 2016;11: e0158332.

2. Fowler RA, Sabur N, Li P, Juurlink DN, Pinto R, Hladunewich MA, et al. Sexand age-based differences in the delivery and outcomes of critical care. Can Med Assoc J. 2007;177:1513-9.

3. Gomez D, Haas B, de Mestral C, Sharma S, Hsiao M, Zagorski B, et al. Gender-associated differences in access to trauma center care: a population-based analysis. Surgery. 2012;152:179-85.

4. Bönte M, von dem Knesebeck O, Siegrist J, Marceau L, Link C, Arber S, et al. Women and men with coronary heart disease in three countries: are they treated differently? Womens Health Issues. 2008;18:191-8.

5. Phelan SM, Hardeman RR. Health professionals' pain management decisions are influenced by their role (nurse or physician) and by patient gender, age and ethnicity. Evid Based Nurs. 2015;18:58.

6. Valentin A, Jordan B, Lang T, Hiesmayr M, Metnitz PG. Gender-related differences in intensive care: a multiple-center cohort study of therapeutic interventions and outcome in critically ill patients. Crit Care Med. 2003;31:1901-7.

7. Pompermaier L, Steinvall I, Fredrikson M, Sjoberg F. Inclusion of coexisting morbidity in a TBSA\% and age based model for the prediction of mortality after burns does not increase its predictive power. Burns. 2015;41:1868-76.

8. Galeiras R, Lorente JA, Pertega S, Vallejo A, Tomicic V, de la Cal MA, et al. A model for predicting mortality among critically ill burn victims. Burns. 2009; 35:201-9.

9. Roberts G, Lloyd M, Parker M, Martin R, Philp B, Shelley O, et al. The Baux score is dead. Long live the Baux score: a 27-year retrospective cohort study of mortality at a regional burns service. J Trauma Acute Care Surg. 2012;72:251-6.

10. Peck MD. Epidemiology of burns throughout the world. Part l: distribution and risk factors. Burns. 2011;37:1087-100.

11. Battle CE, Evans V, James K, Guy K, Whitley J, Evans PA. Epidemiology of burns and scalds in children presenting to the emergency department of a regional burns unit: a 7-year retrospective study. Burns Trauma. 2016;4:19.

12. Kemp AM, Jones $S$, Lawson Z, Maquire SA. Patterns of burns and scalds in children. Arch Dis Child. 2014;99:316-21. 
13. Chang EJ, Edelman LS, Morris SE, Saffle JR. Gender influences on burn outcomes in the elderly. Burns. 2005;31:31-5.

14. Kerby JD, McGwin G Jr, George RL, Cross JA, Chaudry IH, Rue LW 3rd. Sex differences in mortality after burn injury: results of analysis of the National Burn Repository of the American Burn Association. J Burn Care Res. 2006;27: 452-6.

15. George RL, McGwin G Jr, Schwacha MG, Metzger J, Cross JM, Chaudry IH, et al. The association between sex and mortality among burn patients as modified by age. J Burn Care Rehabil. 2005;26:416-21.

16. Queiroz LF, Anami EH, Zampar EF, Tanita MT, Cardoso LT, Grion CM. Epidemiology and outcome analysis of burn patients admitted to an intensive care unit in a university hospital. Burns. 2016;42:655-62.

17. McGwin G Jr, George RL, Cross JM, Reiff DA, Chaudry IH, Rue LW 3rd. Gender differences in mortality following burn injury. Shock. 2002;18:311-5.

18. O'Keefe GE, Hunt JL, Purdue GF. An evaluation of risk factors for mortality after burn trauma and the identification of gender-dependent differences in outcomes. J Am Coll Surg. 2001;192:153-60.

19. Barret JP, Gomez P, Solano I, Gonzalez-Dorrego M, Crisol FJ. Epidemiology and mortality of adult burns in Catalonia. Burns. 1999:25:325-9.

20. Moore EC, Pilcher D, Bailey M, Cleland H. Women are more than twice as likely to die from burns as men in Australia and New Zealand: an unexpected finding of the burns evaluation and mortality (BEAM) study. J Crit Care. 2014;29:594-8

21. Steinvall I, Fredrikson M, Bak Z, Sjoberg F. Mortality after thermal injury: no sex-related difference. J Trauma. 2011;70:959-64.

22. Samuelsson C, Sjoberg F, Karlstrom G, Nolin T, Walther SM. Gender differences in outcome and use of resources do exist in Swedish intensive care, but to no advantage for women of premenopausal age. Crit Care. 2015;19:129.

23. Sjoberg F, Danielsson P, Andersson L, Steinwall I, Zdolsek J, Ostrup L, et al. Utility of an intervention scoring system in documenting effects of changes in burn treatment. Burns. 2000;26:553-9.

24. Abdelrahman I, Elmasry M, Steinvall I, Fredrikson M, Sjoberg F. Improvement in mortality at a National Burn Centre since 2000: was it the result of increased resources? Medicine (Baltimore). 2017:96:e6727.

25. Steinvall I, Bak Z, Sjoberg F. Acute respiratory distress syndrome is as important as inhalation injury for the development of respiratory dysfunction in major burns. Burns. 2008:34:441-51.

26. Liffner G, Bak Z, Reske A, Sjoberg F. Inhalation injury assessed by score does not contribute to the development of acute respiratory distress syndrome in burn victims. Burns. 2005;31:263-8.

27. Bak Z, Sjoberg F, Eriksson O, Steinvall I, Janerot-Sjoberg B. Hemodynamic changes during resuscitation after burns using the Parkland formula. J Trauma. 2009;66:329-36.

28. Janzekovic Z. A new concept in the early excision and immediate grafting of burns. J Trauma. 1970;10:1103-8.

29. Herndon DN, Barrow RE, Rutan RL, Rutan TC, Desai MH, Abston S. A comparison of conservative versus early excision. Therapies in severely burned patients. Ann Surg. 1989;209:547-52. discussion 52-3

30. Still J, Donker K, Law E, Thiruvaiyaru D. A program to decrease hospital stay in acute burn patients. Burns. 1997;23:498-500.

31. Carayon P, Gurses AP. A human factors engineering conceptual framework of nursing workload and patient safety in intensive care units. Intensive Crit Care Nurs. 2005;21:284-301.

32. Morris R, MacNeela P, Scott A, Treacy P, Hyde A. Reconsidering the conceptualization of nursing workload: literature review. J Adv Nurs. 2007;57:463-71.

33. van Oostveen CJ, Vermeulen H, Gouma DJ, Bakker PJ, Ubbink DT. Explaining the amount of care needed by hospitalised surgical patients: a prospective time and motion study. BMC Health Serv Res. 2013;13:42

34. Helmer FT. Patient classification systems in burn care. J Burn Care Rehabil. 1986;7:511-20.

35. Ravat F, Percier $L$, Akkal R, Morris W, Fontaine M, Payre J, et al. Working time and workload of nurses: the experience of a burn center in a high income country. Burns. 2014;40:1133-40.

36. Padilha KG, Sousa RM, Kimura M, Miyadahira AM, da Cruz DA, Vattimo Mde $F$, et al. Nursing workload in intensive care units: a study using the Therapeutic Intervention Scoring System-28 (TISS-28). Intensive Crit Care Nurs. 2007;23:162-9

37. de Jong AE, Leeman J, Middelkoop E. Development of a nursing workload measurement instrument in burn care. Burns. 2009:35:942-8.
38. Driscoll DM. Burn dressings: a critical indicator for patient care classification in burn units. Mil Med. 1991:156:654-7.

39. Brusselaers N, Monstrey S, Vogelaers D, Hoste E, Blot S. Severe burn injury in Europe: a systematic review of the incidence, etiology, morbidity, and mortality. Crit Care. 2010;14:R188.

40. Steinvall I, Elmasry M, Fredrikson M, Sjoberg F. Standardised mortality ratio based on the sum of age and percentage total body surface area burned is an adequate quality indicator in burn care: an exploratory review. Burns. 2016;42:28-40.

41. Hjortso E, Buch T, Ryding J, Lundstrom K, Bartram P, Dragsted L, et al. The nursing care recording system. A preliminary study of a system for assessment of nursing care demands in the ICU. Acta Anaesthesiol Scand. 1992;36:610-4.

42. Smolle C, Cambiaso-Daniel J, Forbes AA, Wurzer P, Hundeshagen G, Branski $L K$, et al. Recent trends in burn epidemiology worldwide: a systematic review. Burns. 2017:43:249-57.
Ready to submit your research? Choose BMC and benefit from:

- fast, convenient online submission

- thorough peer review by experienced researchers in your field

- rapid publication on acceptance

- support for research data, including large and complex data types

- gold Open Access which fosters wider collaboration and increased citations

- maximum visibility for your research: over $100 \mathrm{M}$ website views per year

At BMC, research is always in progress.

Learn more biomedcentral.com/submissions 